\title{
Premenstrual syndrome (PMS) among high school students
}

\author{
This article was published in the following Dove Press journal: \\ International Journal of Women's Health \\ 21 July 2017 \\ Number of times this article has been viewed
}

\section{Nattapong Buddhabunyakan \\ Srinaree Kaewrudee \\ Chompilas Chongsomchai \\ Sukree Soontrapa \\ Woraluk Somboonporn \\ Jen Sothornwit}

Department of Obstetrics and Gynaecology, Faculty of Medicine, Khon Kaen University, Khon Kaen, Thailand
Correspondence: Srinaree Kaewrudee Department of Obstetrics and Gynaecology, Faculty of Medicine, Khon Kaen University, Khon Kaen, Thailand Tel +6643363029

Fax +66 43348395

Email ksrina@kku.ac.th
Background: Premenstrual syndrome (PMS) is a common health problem among adolescents. Objective: To assess the prevalence of PMS in Thai high school students.

Materials and methods: This was a prospective study conducted among menstruating high school students in Khon Kaen, Thailand, from September to December, 2015. Participants were asked to prospectively complete an anonymous questionnaire, which included information about demographic data, menstrual patterns, and symptoms to be recorded on a daily calendar of premenstrual experiences according to the diagnostic criteria proposed by the American College of Obstetricians and Gynecologists. All of the data were prospectively recorded for 90 consecutive days.

Results: Of the 399 participants, 289 (72.4\%) completed the self-report questionnaire. Eighty-six participants $(29.8 \%$; 95\% CI, 24.5\%-35.4\%) reported having PMS. The most common somatic and affective symptoms among participants with PMS were breast tenderness (74.4\%) and angry outbursts $(97.7 \%)$. There were significant differences between the PMS and non-PMS groups, and PMS was associated with various problems related to educational activities, including lack of concentration and motivation, poor individual work performance, poor collaborative work performance, and low scores. However, there were no significant differences regarding interpersonal relationships between the PMS and non-PMS groups.

Conclusions: PMS is a common menstrual disorder among Thai high school students. The most common symptoms reported in this study were angry outbursts and breast tenderness.

Keywords: premenstrual symptoms, prevalence, association, high school students

\section{Introduction}

Premenstrual syndrome (PMS) is a cyclic phenomenon of somatic and affective symptoms appearing in the days preceding menses and interfering with one's work or lifestyle followed by a symptom-free interval. ${ }^{1}$ PMS is variously defined. ${ }^{2}$ The American College of Obstetricians and Gynecologists (ACOG) defined PMS as a clinical condition characterized by the cyclic presence of physical and emotional symptoms unrelated to any organic disease that appear during the 5 days before menses in each of the three prior menstrual cycles and disappear within 4 days of the onset of menses, without recurrence until at least cycle day $13 .^{3}$ Additionally, the American Psychiatric Association (APA) has also established criteria for the diagnosis of severe PMS or premenstrual dysphoric disorder (PMDD). ${ }^{4}$ Women are diagnosed with PMDD when their lives are significantly affected by moderate to severe symptoms as defined in the Diagnostic and Statistical Manual of Mental Disorders, fifth edition. ${ }^{4}$

The prevalence of PMS among adolescents varies from $10 \%$ to $53 \%$, depending on the population studied and diagnostic measures used..$^{-10}$ For example, $\sim 10 \%$ and $3 \%$ of the participants in a Swiss Study experienced PMS and PMDD, respectively. ${ }^{7}$ 
In a Japanese study, prevalence rates of moderate to severe PMS and PMDD were 53\% and $1.2 \%$, respectively. ${ }^{8}$ In a previous US population-based study, prevalence rates of PMS and PMDD were $8 \%$ and 5\%, respectively. ${ }^{9}$ Women with PMS tend to have a significantly lower quality of life, increased absenteeism from work, decreased work productivity, impaired relationships with others, and more frequent visits to health providers than those who do not experience PMS. ${ }^{10}$

As there have yet been no prospective studies evaluating PMS prevalence among Thai adolescents according to the recent ACOG diagnostic criteria, this study was conducted to determine the prevalence of PMS and its impacts on educational activities and interpersonal relationships among Thai adolescents in Khon Kaen, Thailand.

\section{Materials and methods}

The study was conducted from September to December, 2015, with the approval of the Khon Kaen University Ethics Committee. We recruited 399 menstruating upper high school students (10th to 12th grade) in Khon Kaen, Thailand. A cluster sampling method was applied in enrolling the participants. The target sample size was estimated to be 399 , on the basis of an $80 \%$ power and $95 \%$ CI for the expected prevalence of $50 \%$, with $10 \%$ loss to follow-up. Eligible criteria included: 1) age 15-18 years and 2) regular menstrual cycles (21-35 days). Participants were excluded if they had histories of: 1) medical problems including thyroid disorders, autoimmune disease, asthma, adrenal disorders, or epilepsy; 2) untreated depression or psychiatric disorders; 3) gynecologic problems including endometriosis or pelvic inflammatory disease; or 4) using hormonal medication such as oral contraceptive pills. The parents or guardians of the participating students provided written informed consent.

Diagnosis of PMS in this study was made according to the diagnostic criteria proposed by the ACOG. ${ }^{3}$ PMS can be diagnosed if the patient reports at least one of the following affective symptoms including depression, angry outbursts, irritability, anxiety, confusion, or social withdrawal and at least one of somatic symptoms including breast tenderness, abdominal bloating, headache, or swelling of extremities during the 5 days before menses in each of the three prior menstrual cycles. In addition, these symptoms are typically relieved within 4 days of the onset of menses, without recurrence until at least cycle day 13 . The symptoms are present in the absence of any pharmacologic therapy, hormone ingestion, or drug or alcohol use. ${ }^{3}$ The symptoms must reproducibly occur during two cycles of the prospective records. ${ }^{3}$ We applied the ACOG PMS questionnaires and the diary calendar of premenstrual experiences in collecting the data. ${ }^{11}$ The questionnaires were translated into Thai by the researchers and translated back into English by professional translators. The questionnaires and diary calendar were then sent to three professionals for assessment validation using the Item Objective Congruence index. An acculturated pilot study was conducted to improve the questionnaire quality. The questionnaires consisted of four sections. The first part consisted of demographic data questions including age, weight, height, exercise habits, coffee consumption, cigarette smoking, and alcohol consumption. The second part included gynecological history, menstrual patterns, and dysmenorrhea. The third part included prospective symptoms on a diary calendar, which was constructed on the basis of ACOG PMS diagnostic criteria. The last part contained questions about the association with educational activities and interpersonal relationships.

The severity of PMS symptoms was rated by the participants on the basis of their impacts on their daily lives, ranging from mild to moderate to severe. Mild symptoms were defined as not limiting daily activity. Symptoms were considered moderate if there were marked limitations with regard to daily activity, and severe if the participants were unable to carry out the activities without discomfort. The anonymous questionnaires and attached consent forms were then distributed to the students, and participants were asked to record their symptoms for 90 days.

Statistical analysis was carried out using SPSS software (IBM, Armonk, NY, USA). Descriptive statistics, including mean $\pm \mathrm{SD}$ or percentage, were used when appropriate for reporting demographic data, prevalence of PMS, prevalence of impaired educational activity, and prevalence of impaired interpersonal relationships. A 95\% CI of the prevalence of PMS was calculated to determine the precision of the primary outcome. The associations between PMS and participants' educational activities and interpersonal relationships were analyzed via the $\chi^{2}$ or Fisher's exact test, as appropriate. Statistical significance was set at $P<0.05$.

\section{Results}

Of the 399 participants who met the inclusion criteria, 289 filled out the self-report questionnaire completely, amounting to a response rate of 72.4\%. Applying the ACOG guidelines, PMS was diagnosed in 86 participants $(29.8 \%$; 95\% CI, 24.5\%-35.4\%). Characteristics of the participants in the PMS and non-PMS groups are shown in Table 1. There were no differences in participants' baseline characteristics 
Table I Characteristics of participants

\begin{tabular}{|c|c|c|}
\hline Characteristics & $\begin{array}{l}\text { PMS group } \\
(\mathrm{n}=86)\end{array}$ & $\begin{array}{l}\text { Non-PMS group } \\
(\mathrm{n}=203)\end{array}$ \\
\hline Age (years) & $16.5 \pm 1.0$ & $16.4 \pm 1.1$ \\
\hline \multicolumn{3}{|l|}{ BMI $\left(\mathrm{kg} / \mathrm{m}^{2}\right)$} \\
\hline Underweight & $26(30.2)$ & $67(33.0)$ \\
\hline Normal & $50(58.1)$ & $108(53.2)$ \\
\hline Overweight & $6(7.0)$ & $15(7.4)$ \\
\hline Obese & $4(4.7)$ & $13(6.4)$ \\
\hline \multicolumn{3}{|l|}{ Education } \\
\hline Grade 10 & $28(32.6)$ & $90(44.3)$ \\
\hline Grade II & $32(37.2)$ & $36(17.7)$ \\
\hline Grade 12 & $26(30.2)$ & $77(37.9)$ \\
\hline \multicolumn{3}{|l|}{ Exercise } \\
\hline Adequate ( $\geq 3$ times/week) & $32(37.2)$ & $67(33.0)$ \\
\hline Inadequate ( $<3$ times/week) & $54(62.8)$ & $136(67.0)$ \\
\hline \multicolumn{3}{|l|}{ Coffee consumption } \\
\hline Yes & $29(33.7)$ & $66(32.5)$ \\
\hline No & $57(66.3)$ & $137(67.5)$ \\
\hline \multicolumn{3}{|l|}{ Alcohol consumption } \\
\hline Yes & $4(4.7)$ & $12(5.9)$ \\
\hline No & $82(95.3)$ & $191(94.1)$ \\
\hline \multicolumn{3}{|l|}{ Cigarette smoking } \\
\hline Yes & $0(0)$ & $0(0)$ \\
\hline No & $86(100.0)$ & $203(100.0)$ \\
\hline \multicolumn{3}{|l|}{ Menstruation } \\
\hline Menarche (year) & $12.3 \pm 1.1$ & $12.3 \pm 1.1$ \\
\hline \multicolumn{3}{|l|}{ Dysmenorrhea } \\
\hline Present & $65(75.6)$ & $153(75.4)$ \\
\hline Absent & $21(24.4)$ & $50(24.6)$ \\
\hline
\end{tabular}

Note: Data are presented as numbers (percentage) or mean \pm SD.

Abbreviations: BMI, body mass index; PMS, premenstrual syndrome.

including age, body mass index, exercise, alcohol consumption, and coffee consumption between the PMS and non-PMS groups. Dysmenorrhea was the most common abnormal menstrual symptom in both groups (75.6\% in the PMS group and $75.4 \%$ in the non-PMS group).

Two hundred forty-eight participants $(85.8 \%)$ reported having at least one of the 10 symptoms of PMS. The reported premenstrual somatic and affective symptoms and their frequency among the 85 participants with PMS are presented in Table 2. The three most common somatic symptoms were breast tenderness $(74.4 \%)$, headache $(70.9 \%)$, and abdominal bloating (46.5\%). The three most common affective symptoms were angry outbursts $(97.7 \%)$, anxiety $(73.3 \%)$, and irritability (68.6\%). In most cases, these symptoms were rated as mild to moderate in severity.

The impacts of PMS on educational activities and interpersonal relationships are reported in Table 3. PMS was significantly associated with several problems regarding educational activity, as shown by lack of concentration and motivation, poor work performance, and low scores. However, PMS
Table 2 Prevalence of premenstrual somatic and affective symptoms of PMS ( $\mathrm{N}=86)$

\begin{tabular}{|c|c|c|c|c|}
\hline \multirow[t]{2}{*}{ Symptoms } & \multirow{2}{*}{$\begin{array}{l}\text { Total } \\
\text { prevalence }^{a}\end{array}$} & \multicolumn{3}{|c|}{ Severity of symptoms ${ }^{b}$} \\
\hline & & Mild & Moderate & Severe \\
\hline \multicolumn{5}{|l|}{ Somatic } \\
\hline Breast tenderness & $64(74.4)$ & $28(43.7)$ & $33(5 \mathrm{I} .6)$ & $3(4.7)$ \\
\hline Headache & $61(70.9)$ & $36(59.0)$ & $20(32.8)$ & $5(8.2)$ \\
\hline Abdominal bloating & $40(46.5)$ & $21(52.5)$ & $17(42.5)$ & $2(5.0)$ \\
\hline Swelling extremities & $18(20.9)$ & $13(72.2)$ & $5(27.8)$ & $0(0.0)$ \\
\hline \multicolumn{5}{|l|}{ Affective } \\
\hline Angry outbursts & $84(97.7)$ & $28(33.3)$ & $50(59.5)$ & $6(7.1)$ \\
\hline Anxiety & $63(73.3)$ & $42(66.7)$ & $21(33.3)$ & $0(0.0)$ \\
\hline Irritability & $59(68.6)$ & $23(39.0)$ & $32(54.2)$ & $4(6.8)$ \\
\hline Depression & $42(48.8)$ & $29(69.0)$ & $13(3 \mid .0)$ & $0(0.0)$ \\
\hline Confusion & $37(43.0)$ & 34 (91.9) & $3(8.1)$ & $0(0.0)$ \\
\hline Social withdrawal & $31(36.0)$ & $20(64.5)$ & II (35.5) & $0(0.0)$ \\
\hline
\end{tabular}

Notes: ${ }^{a} \geq I$ symptom/student. ${ }^{b} O n$ the basis of self-rating by participants, these are classified according to three levels, as follows: mild (no limitation of daily activity), moderate (marked limitation of daily activity), and severe (unable to carry out daily activity without discomfort). Data are presented as number (\%).

Abbreviation: PMS, premenstrual syndrome.

was not associated with absenteeism, difficulty in working, or the quality of interpersonal relationships.

Forty-six (46.4\%) of the participants in the PMS group reported that they self-administered treatment. The most common coping methods were analgesic drugs (38.4\%) and recreational activities (26.3\%). The participants also consulted their friends (33.9\%) and their parents $(22.8 \%)$ when they were suffering from these symptoms. Only 3\% of them sought medical consultation.

\section{Discussion}

The prevalence of PMS in Thai high school students in this study was $\sim 30 \%$. PMS frequently occurs among women with high stress levels. Prolonged stress exposure could lead to

Table 3 Association of PMS with moderate-to-severe impairments affecting educational activities and interpersonal relationships

\begin{tabular}{llll}
\hline Factors & $\begin{array}{l}\text { PMS } \\
\text { group }\end{array}$ & $\begin{array}{l}\text { Non-PMS } \\
\text { group }\end{array}$ & \\
\hline $\begin{array}{llll}\text { Educational activities } \\
\text { Lack of concentration }\end{array}$ & $40(46.5)$ & $69(34.0)$ & 0.045 \\
$\quad$ Lack of motivation & $42(48.8)$ & $57(28.1)$ & 0.00 I \\
Poor individual work performance & $44(48.8)$ & $74(36.5)$ & 0.020 \\
$\quad \begin{array}{llll}\text { Poor collaborative work performance } \\
\text { Low scores }\end{array}$ & $43(38.4)$ & $45(22.2)$ & 0.005 \\
Absenteeism & $7(8.1)$ & $26(12.8)$ & 0.254 \\
Difficulty in working and activities & $9(10.5)$ & $22(10.8)$ & 0.925 \\
Interpersonal relationship & & & \\
$\quad \begin{array}{llll}\text { Poor relationships with friends } \\
\text { Poor relationship with family }\end{array}$ & $6(7.0)$ & $23(11.3)$ & 0.260 \\
Social withdrawal & $5(5.8)$ & $22(10.8)$ & 0.180 \\
\hline
\end{tabular}

Note: Data are presented as number (\%).

Abbreviation: PMS, premenstrual syndrome. 
persistent malfunctions of the neuroendocrine system and trigger PMS. ${ }^{12}$ Adolescents are in the process of undergoing tremendous physical and psychological changes on their way to adulthood. Moreover, they frequently experience stress related to their studies, as well as their sexual and reproductive health. The most frequent somatic symptoms were breast tenderness (74.4\%). The most frequent affective symptoms included angry outbursts (97.7\%), anxiety (73.3\%), and irritability (68.6\%), which was similar to previously reported findings among adolescents. ${ }^{6,8-10}$

In the present study, a considerably high proportion of participants reported having at least one PMS symptom $(86 \%)$. It has been suggested that the etiology of PMS is multifactorial. Several factors associated with PMS have been proposed, including social factors, that is, ethnicity and culture, socioeconomic status, cigarette smoking, alcohol consumption, exercise, dietary habits, and menstrual factors (ie, age at menarche and menstrual patterns). ${ }^{13-16}$

The variation in the prevalence of PMS across studies might be due to differences in ethnicity and culture, diagnostic criteria, types of studied populations, and data collection methods used.,17 Theoretically, accurate PMS diagnosis requires the prospective daily charting of symptoms, which is a time-consuming task. Most studies, however, were based only on retrospective self-reporting, which could lead to recall bias. In this study, the diagnosis of PMS was made on the basis of prospective daily recording of symptoms for 90 consecutive days, thus increasing the value of this study.

This study observed that PMS was significantly associated with several problems related to educational activities, including lack of concentration, lack of motivation, decreased individual or collaborative work performance, and low scores. These findings were consistent with the findings from previous studies. ${ }^{18-21}$ Most participants, however, were rarely concerned about these symptoms due to their low levels of severity. As we found in the study, only a small proportion of participants consulted their friends (33.9\%) or parents (22.8\%) regarding PMS. This is in contrast to the results of a study by Lee et al, ${ }^{20}$ which found that $80 \%$ of participants consulted their mothers and $\sim 40 \%$ consulted their friends regarding PMS. In addition, few participants (3.1\%) in this study had consulted their physicians for PMS, which was similar to findings from a previous study by Sharma et $\mathrm{al}^{21}$ in which PMS was evaluated in Indian adolescents (4\%).

There are a number of limitations in this study. First, self-rating of affective symptoms may be somewhat difficult for adolescents, which may raise concerns about the reliability of the data. Second, no clinical/psychiatric diagnosis to exclude underlying mental health problems was carried out in this study. Third, data regarding the pattern of PMS symptoms changed over the time were unavailable in the present study. However, the strengths of this study were that it was a prospective one, it used a standard daily calendar for prospective recording, and its criteria for PMS diagnosis were strict. To our knowledge, this is the first study in Thailand to apply prospective data and the self-recording of symptoms to diagnose PMS.

The notably high prevalence of PMS in Thai adolescents observed in this study warrants further large-scale study to evaluate the impact of PMS on their academic performance, quality of life, and effective interventions for alleviating PMS among this high-risk population.

\section{Conclusion}

The prevalence of PMS in Thai high school students was $29.8 \%$ (95\% CI, 24.5\%-35.4\%). The most frequent symptoms included breast tenderness and angry outbursts. PMS had a significant negative association with various educational activities.

\section{Acknowledgment}

The authors are grateful to Dylan Southard for his assistance in editing this manuscript. This study received a research grant from the Khon Kaen University Faculty of Medicine.

\section{Disclosure}

The authors report no conflicts of interest in this work.

\section{References}

1. Speroff L, Fritz MA. Menstrual disorder. Clinical Gynecologic Endocrinology and Infertile. 8th ed. Philadelphia, PA: Lippincott Williams \& Wilkins; 2011:568-578.

2. Frank RT. The hormonal causes of premenstrual tension. Arch Neurol Psychiatr. 1931;26:1052-1057.

3. ACOG Practice Bulletin. Premenstrual syndrome. Clinical management guidelines for obstetrician - gynecologists. Number 15. JObstet Gynecol. 2001;73:183-191.

4. American Psychiatric Association. Diagnostic and Statistical Manual of Mental Disorders. 5th ed. Washington, DC: APA Press; 2012: 465-475.

5. Tschudin S, Bertea P, Zemp E. Prevalence and predictors of premenstrual syndrome and premenstrual dysphoric disorder in a population-based sample. Arch Womens Ment Health. 2010;13(6):485-494.

6. Takeda T, Koga S, Yaegashi N. Prevalence of premenstrual syndrome and premenstrual dysphoric disorder in Japanese high school students. Arch Womens Ment Health. 2010;13(6):535-537.

7. Deuster PA, Adera T, South-Paul J. Biological, social, and behavioral factors associated with premenstrual syndrome. Arch Fam Med. 1999;8(2): $122-128$

8. Ogebe O, Abdulmalik J, Bello-Mojeed M, et al. A comparison of the prevalence of premenstrual dysphoric disorder and comorbidities among adolescents in the United States of America and Nigeria. J Pediatr Adolesc Gynecol. 2011;24(6):397-403. 
9. Chau JP, Chang AM, Chang AM. Relationship between premenstrual tension syndrome and anxiety in Chinese adolescents. J Adolesc Health. 1998;22(3):247-249.

10. Rapkin AJ, Mikacich JA. Premenstrual dysphoric disorder and severe premenstrual syndrome in adolescents. Pediatr Drugs. 2013;15(3): 191-202.

11. Freeman E. Premenstrual syndrome and premenstrual dysphoric disorder: definitions and diagnosis 11 adapted from the symposium on premenstrual syndrome and premenstrual dysphoric disorder. Psychoneuroendocrinology. 2003;28:25-37.

12. Roca CA, Schmidt PJ, Altemus M, et al. Differential menstrual cycle regulation of hypothalamic-pituitary-adrenal axis in women with premenstrual syndrome and controls. J Clin Endocrinol Metab. 2003;88(7): 3057-3063.

13. Nour M, Mahnaz N, Golbahar K. Prevalence and severity of premenstrual symptoms among Iranian female university students. J Pak Med Assoc. 2009;59(4):205-208.

14. Steiner M, Born L. Diagnosis and treatment of premenstrual dysphoric disorder: an update. Int Clin Psychopharmacol. 2000;15(3):5-17.

15. Rowland A, Baird D, Long S, Wegienka G, Harlow S, Alavanja M, et al. Influence of medical conditions and lifestyle factors on the menstrual cycle. Epidemiology. 2002;13(6):668-674.
16. Dennerstein L, Lehert P, Bäckström T, Heinemann K. Premenstrual symptoms - severity, duration and typology: an international crosssectional study. Menopause Int. 2009;15(3):120-126.

17. Pinar G, Colak M, Oksuz E. Premenstrual syndrome in Turkish college students and its effects on life quality. Sex Reprod Health. 2011; 2(1):21-27.

18. Tenkir A, Fisseha N, Ayele B. Premenstrual syndrome, prevalence and effect on academic and social performances of students in Jimma University, Ethiopia. Ethiop J Health Dev. 2003;17:181-188.

19. Yang M, Wallenstein G, Hagan M, Guo A, Chang J, Kornstein S. Burden of premenstrual dysphoric disorder on health-related quality of life. J Womens Health. 2008;17(1):113-121.

20. Lee LK, Chen PC, Lee KK, Kaur J. Menstruation among adolescent girls in Malaysia: a cross-sectional school survey. Singapore Med J. 2006;47(10):869-874.

21. Sharma P, Malhotra C, Taneja DK, Saha R. Problems related to menstruation among adolescent girls. Indian J Pediatr. 2008;75(2):125-129.
International Journal of Women's Health

\section{Publish your work in this journal}

The International Journal of Women's Health is an international, peerreviewed open-access journal publishing original research, reports, editorials, reviews and commentaries on all aspects of women's healthcare including gynecology, obstetrics, and breast cancer. The manuscript management system is completely online and includes

\section{Dovepress}

a very quick and fair peer-review system, which is all easy to use. Visit http://www.dovepress.com/testimonials.php to read real quotes from published authors.

\footnotetext{
Submit your manuscript here: http://www.dovepress.com/international-journal-of-womens-health-journal
} 